\title{
SOBRE EL CONOCIMIENTO DEL GRIEGO EN LAS ABADÍAS DE JARROW Y SANKT GALLEN EN ÉPOCA MEDIEVAL: EL LITERALISMO EN LA TRADUCCIÓN
}

\section{Lorenzo MARTÍNEZ ÁNGEL}

\author{
Dedicado a la querida memoria \\ de D. José Méndez Grande y Señora.
}

La historia del conocimiento del griego, con todo lo que ello implica, dentro del ámbito del monacato occidental es un tema lleno de cuestiones de interés, incluso en ocasiones sorprendentes ${ }^{1}$. En este trabajo analizaremos solamente dos casos de época altomedieval.

\section{Una indicación autobiográfica de Beda el Venerable}

Al final de su Historia Ecclesiastica gentis Anglorum Beda el Venerable escribió unas pocas noticias autobiográficas referidas no sólo a su vida sino también a su trabajo intelectual. Y una de ellas es la que comentaremos. Dice así: Item de historiis sanctorum: librum vitae et passionis sancti Felicis confessoris de metrico Paulini opere in prosam transtuli; librum vitae et passionis sancti Anastasii, male de Greco translatum et peius a quodam imperito emendatum, prout potui, ad sensum correxi...3.

Sabido es el conocimiento que Beda tuvo de la lengua griega ${ }^{4}$ y que en su

${ }^{1}$ Recordemos, por citar sólo un ejemplo, que la primera vez que fueron representados caracteres griegos en letras de molde fue en el mismo Subiaco, en octubre de 1465, por dos impresores alemanes.

${ }^{2}$ Personalidad de presentación innecesaria, y del que se ha escrito lo siguiente: "sin duda fue un producto del cristianismo celta irlandés en tierras de Inglaterra, en una región ajena a la tradición latina. La tarea de Beda se desarrolló en algunas de las escuelas de Northumbria en que había tenido lugar el encuentro entre misioneros irlandeses y romanos" (Javier García Turza, La transmisión cultural hispana y el Renacimiento Carolingio: La Enseñanza en la Edad Media. X Semana de Estudios Medievales, Logroño 2000, 17-38, concretamente p.24). A esta rica mezcla de influencias se añadirá, como veremos después, el conocimiento del griego llevado por los misioneros romanos.

${ }^{3}$ Beda Venerabilis, Historia Ecclesiastica gentis Anglorum, V, XXIV.

${ }^{4}$ García M. Colombás, La tradición benedictina. Ensayo histórico. Tomo tercero: Los siglos VIII-XI, Zamora 1991, 204: "Se las ingenió como pudo -con método y esfuerzo- para llegar a dominar la lengua griega; por eso pudo dedicar parte de sus comentarios bíblicos a la crítica textual, por la que muestra gran interés, comparando las lecturas de los manuscritos que pudo consultar". El conocimiento del griego en Inglaterra a partir del siglo VII se debe, como es sabido, a Teodoro de Tarso (o de Canterbury), prelado de origen griego (André Guillou, Bizancio y los orígenes de la Europa Occidental: VV. AA., Carlomagno y Mahoma, Madrid 1987, pp.23-100, concretamente p.31).

${ }^{4}$ Fray Justo Pérez de Urbel, Las grandes abadias benedictinas, Madrid, c. 1928, 189-190: "La biblioteca era una de las grandes riquezas de Yarrow. Siempre que salía de viaje volvía el fundador [San Benito Biscop] cargado de libros. Eran libros latinos, griegos y celtas, de los doctores antiguos y modernos, cristianos y paganos, y no faltaban tampoco las Escrituras en hebreo. [...] El 
abadía de Jarrow la biblioteca estaba bien surtida, contando también con códices en griego y otras lenguas distintas de la latina y de diversas procedencias. Pues bien, consideramos que esta mala traducción a la que hace referencia en el texto citado, y peor enmendada por un inexperto, que él corrige ("en la medida que pude") según el sentido, no sería otra cosa que un probable reflejo del literalismo tan frecuente en la traducción de textos en época medieval. Los ejemplos, si bien unos más claros que otros, que dan muestra de ello son abundantes y variados en cronología y origen geográfico. Así, por citar sólo tres casos, mencionaremos uno irlandés, un segundo hispano y un tercero itálico, al que añadire mos, en la segunda parte de este trabajo, un ejemplo germano. Con respecto al primero, cabe mencionar el Evangeliario grecoirlandés conservado en la abadía de Sankt Gallen, donde puede verse cómo la traducción latina intertextual está realizada palabra a palabra, es decir, sobre el término griego aparece su traducción latina.

Por lo que se refiere al caso hispánico, en realidad no sería un ejemplo, sino múltiples, procedentes de la Escuela de Traductores de Toledo, lo cual ha sido bien estudiado por Mohamed El Madkouri Maataqui, analizando el literalismo de las traducciones allí producidas, sus tipos y sus causas, entre las que menciona "el poco dominio de una o de las dos lenguas de contacto, el desconocimiento de las técnicas del oficio y la poca aprehensión del tema traducido"5, además de la "pretensión de fidelidad"6.

En cuanto al ejemplo itálico, se refiere a la traducción al latín de los cánones orientales realizada por Dionisio el Exiguo entre los siglos V y VI: “¿Cuál fue, pues, el proceso de actividad de Dionisio el Exiguo? Hacia el 500 Dionisio había concluido en Roma la primera traducción latina de los cánones orientales: al mismo tiempo desempolvaba algunas cartas Decretales de los Papas de los archivos de la chancillería pontificia. Con esto y los concilios africanos, que iban llegando, poco después formó un todo ordenado: era la primera colección latina de cánones. Mas un estudio posterior advirtió a Dionisio que la traducción de los concilios era más bien un acertijo que otra cosa. Entonces se dedicó a revisar la

\footnotetext{
rey Alfrido, discípulo de los monjes de Yona, miraba con envidia todos aquellos tesoros literarios y científicos de Yarrow. De buena gana se los hubiera llevado a su palacio; pero se le iban especialmente los ojos tras una cosmografía de un trabajo admirable, por la que Benito había dejado en Roma buenos dineros". Tratándose de esta época y de las Islas Británicas no debemos dejar de mencionar la influencia del griego y del hebreo en la cultura latina de la época, que produjo piezas en las que se empleaban junto a los latinos términos hebreos y griegos (The Cambridge History of English an American Literature. I. From the Beginnings to the Cycles of Romance. V. Latin Writings in England to the Time of Alfred. \#2. "Hisperic" Latin.

${ }^{5}$ Mohamed el-Madokouri Maataoui, Las escuelas de traductores en la Edad Media: La Enseñanza en la Edad Media. X Semana de Estudios Medievales, Logroño 2000, 97-127, concretamente p. 127.

${ }^{6}$ Ibid., 120.
} 
obra realizada. El año 514 estaba terminada la nueva empresa: resultó una colección de tendencia literariamente ampulosa"7.

¿Cuál fue la causa de esta mala traducción que debió corregir? Sospechamos que pudo ser, precisamente, el literalismo, tan común en época medieval que conduciría a una traducción con poco sentido en algunas de sus partes y que le obligaría a la revisión mencionada.

Consideramos, por tanto, que lo expresado por Beda indicaría un ejercicio por su parte de dar inteligibilidad a una traducción que probablemente carecería de ella en latín por haber sido realizada bien palabra por palabra, bien con otro tipo de literalismo, con lo cual el sentido se habría perdido, al menos en parte, y esto explicaría que corrigiera ad sensum.

\section{Una frase griega en los casus Sancti Galli}

No es ésta la primera vez que nos ocupamos de aspectos de la cultura griega que había en la abadía suiza de Sankt Gallen. En esta ocasión analizaremos una frase griega incluida en los Casus Sancti Galli (en adelante CSG). El contexto que lo justifica es la enseñanza del griego en la segunda mitad del siglo $X$ por parte de Eduvigis de Baviera a un joven del monasterio de Sankt Gallen Ilamado Burcardo. Ella había recibido enseñanza de griego por haber estado prometida al emperador de Bizancio, pero quiso aprender latín, siendo su profesor Ekkehardo9, quien le presentó al joven Burcardo, el cual impresionó a Eduvigis por su dominio de la composición de versos latinos, los cuales despertaron su simpatía: “La duquesa se echó a reír de la mejor gana del mundo y se encargó muy gustosa de enseñar el griego al muchacho"10. Los CSG explican así cómo fue: Illa vero extra solitam severitatem in cachinos versa, tandem puerum coram se statuit et eum antiphonam 'Maria et flumina' quam ipsam in Grecum transtulit, canere docuit ita: 'Thalassi ke potami, eulogiton kiryon; ymnite pigonton kyrion alleluia'. Crebroque illum postea, cum vacasset, ad se vocatum, repentinis ab eo versibus exactis, grecissare docuit et unice dilexit ${ }^{11}$.

Partiendo de aquí, realizaremos el análisis de las formas del texto griego transliterado en los CSG, comparándolas con las de la Versión de los Setenta de la Biblia:

\footnotetext{
${ }^{7}$ Manuel de la Red, La colección "Hispana”. Formación e influencia de la misma: Studium Legionense 5 (1964) 257-268, concretamente p.261.

${ }^{8}$ Lorenzo Martínez Ángel, "Sobre paleografía medieval greco-irlandesa: una posible influencia de la 'o' romboidal precarolina en una omega del evangeliario grecolatino irlandés de Sankt Gallen (Suiza)”, Alminar (en prensa).

${ }^{9}$ No debe confundirse, a pesar de su homonimia, a este monje con el autor de los CSG.

${ }^{10}$ Fray Justo Pérez de Urbel, o.c., p.181. 2002, 194.

${ }^{11}$ Ekkerhardi IV, Casus Sancti Galli. Editionis textum paravit Hans F. Haefele, Darmstadt
} 


\begin{tabular}{|c|c|}
\hline Casus Sancti G alli & $\begin{array}{l}\text { Versión de los } \\
\text { Setenta }\end{array}$ \\
\hline Thalassi & $\Theta \mathrm{A} \Lambda \mathrm{A} \Sigma \Sigma \mathrm{AI}$ \\
\hline $\mathrm{Ke}$ & KAI \\
\hline Potami & ПОТАМОI \\
\hline Eulogiton & ЕY $\Lambda$ ОГЕITЕ АYТОN \\
\hline Kiryon & KYPION \\
\hline Ymnite & YMNEITE \\
\hline Pigonton & ПНГАІ АYТON \\
\hline Kyrion & KYPION \\
\hline Alleluia & \\
\hline
\end{tabular}

A nalizando las formas fonéticamente, siguiendo el método de trabajo que empleó en 1959 el Catedrático de Griego D. Manuel Rabanal Álvarez en su trabajo sobre las piezas griegas transcritas en el Antifonario Visigótico-Mozárabe de la Catedral de León, comenzaremos por las dos primeras, thalassi y ke, fácimente explicables teniendo en cuenta que ya en la antigüedad $\alpha \iota$ pasaron a pronunciarse $\varepsilon^{12}$. Esto se comprueba, igualmente, en las piezas griegas transcritas del códice leonés anteriormente citado. Por lo que respecta a potami la explicación es similar, pues también o $\iota$ pasó a pronunciarse $t^{13}$. La siguiente palabra presenta mayor dificultad, pues debería corresponder al imperativo presente, o en su defecto al imperativo aoristo, pero no encaja con ninguna de estas dos formas. Personalmente consideramos que la forma que aparece en los CSG muestra en realidad una crasis de EYAOГEITE y AYTON, observándose que la $\imath$ sería la pronunciación de $\varepsilon l^{14}$, de modo similar a los casos anteriores, y exactamente igual que vemos en ymnite. En cuanto a pigonton, esta forma no la hemos encontrado en griego (ni en el bíblico), y pensamos que podría ser otra crasis, en este caso de ПНГАI y $A Y T O N$, teniendo en cuenta la pronunciación como $\imath$ de la $\eta$ (el conocido iotacismo). Bien es cierto que para que fuese la crasis indicada sobraría la $n$ intermedia, pero probablemente estemos ante un error de transcripción en el manuscrito de los CSG, o como definió el Prof. Rabanal Álvarez una transcripción deformante, siguiendo a A. Ernout ${ }^{15}$, las cuales fueron calificadas por el citado helenista leonés como "verdaderas deformaciones, más que peculiaridades transcripcionales". Sobre la forma kyrion huelga cualquier comentario, mientras que kiryon no parece ser más que una simple errata del copista de los CSG.

${ }^{12}$ Blas Goñi, Gramática griega, Pamplona 1941, p.245.

${ }^{13}$ ID., l. c.

${ }^{14}$ ID., l. c.

${ }^{15}$ El trabajo de A. Ernout que cita el Prof. Rabanal Álvarez es "Les mots grecs dans la Peregrinatio Aetheriae", Emerita 20, 1952, 289ss. 
Y la última palabra, Alleluia, nos da pie a comentar el texto que nos ocupa desde otro punto de vista, concretamente en lo referente al tipo de traducción. EI Prof. Haefele localizó perfectamente el origen bíblico del texto (Daniel 3,77-78), pero lo cierto es que se trata de una adaptación litúrgica del texto bíblico, algo muy común y nada extraño. Transcribimos a continuación el texto griego de los Setenta que sirve de base al texto de la antífona:

77)ЕY $\Lambda$ ОГЕITЕ АI ПНГАI TON КYPION YMNEITE KAI YПЕРYЧOYТЕ АY TON EI $\Sigma$ TOY $\Sigma$ AI $\Omega N A \Sigma$.

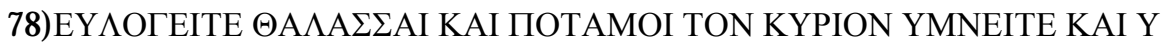
ПЕPYЧOYTE AYTON EI $\Sigma$ TOY $\Sigma$ AI $\Omega N A \Sigma$

Como puede verse, la forma CSG está basada en el texto bíblico, pero variando no sólo el orden de las palabras que aparece en la versión bíblica griega, lo cual es normal teniendo en cuenta que lo que traduce no es ese texto propiamente dicho sino la antífona latina inspirada en el texto veterotestamentario ${ }^{16}$. Más importantes son otras cuestiones lingüísticas, como hacer desaparecer, por ejemplo, todos los artículos, para lo que no tenemos más explicación que la influencia del latín sobre quien redactó los CSG, lo cual podría parecer, de entrada, una respuesta muy satisfactoria, pero que, muy al contrario, no sólo no debe ser desestimada totalmente sino que probablemente sea la explicación, por la razón que ya hemos citado en la primera parte de este trabajo, y es el literalismo de las traducciones, realizadas palabra por palabra, por lo que, no existiendo artículos en la antífona latina que traduce Eduvigis, aplicando la citada técnica, no aparecerían tampoco en la traducción griega. Sería éste, por tanto, un ejemplo de literalismo en las traducciones de época medieval del que nos ocupamos en la primera parte del presente trabajo. Además, en este caso nos preguntamos si la razón del literalismo sería una de las indicadas por el Prof. El-Madokouri Maataoui: "El poco dominio de una o de las dos lenguas de contacto", pues los CSG informan que Eduvigis lo que quería era aprender latín, siendo Ekkehardo su profesor ${ }^{17}$, y todavía lo era cuando sucedió la anécdota referida de Burcardo: ¿qué grado de conocimientos había adquirido Eduvigis en ese momento de la lengua de Roma? Ignoramos la respuesta. No obstante, también hay que tener en cuenta otro factor que no debe olvidarse: la noticia nos ha llegado a través del testimonio de Ekkerhardo IV, el autor de los CSG que citamos, quien escribió bastantes años después del momento que relata, por lo que no sabemos hasta qué punto es absolutamente fidedigno en la transmisión de las palabras de Eduvigis. Sin embargo, también debe tenerse en cuenta que el texto latino de la antífona, correspondiente concretamente a los laudes del Oficio de Santa María es el siguiente: Benedicite fontes Domino: benedicite maria et flumina Domino. El verbo aparece en primer lugar, al igual que en la versión griega. Sin embargo, aten-

${ }^{16}$ Nótese que las partes finales de ambos versículos no aparecen en la traducción de Eduvigis que recogen los CSG.

${ }^{17}$ CSG, p. 186. 
diendo a lo que los mismos CSG indican, es decir, que el texto comienza Maria et flumina, cabe pensar que el orden de las palabras del texto latino sobre el que se realizaría la traducción sería otro, no estando el verbo al principio, lo cual, por cierto, es una forma muy frecuente de ver esta antífona en los textos litúrgicos: Maria et flumina benedicite Domino, fontes benedicite Domino.

En nuestra opinión, parece claro, pues, que la ausencia de artículos se debe al mencionado literalismo. Las palabras escogidas, obviamente, se corresponden con la versión griega. Respecto al orden de palabras, quizá también, pero no queremos dejar de indicar otra posibilidad a tener en cuenta y es que, aunque los CSG indiquen expresamente que Eduvigis tradujo (transtulit) cabría igualmente pensar que en realidad no fue una traducción, en el sentido literal del término, sino que repitió memorísticamente el texto griego equivalente al latino. Esto explicaría, por ejemplo, la diferencia benedicite / ymnite, teniendo además en cuenta que tanto el texto de la Vulgata como de la antífona traducen la mencionada forma verbal griega como laudate ${ }^{18}$. Además, habría una razón para suponer que esta hipótesis es la que explicaría mejor lo que nos dicen los CSG, y sería el detalle que indica que Eduvigis enseñó cantando (canere docuit ita), lo que hace suponer que repitió un texto aprendido con música, lo cual es más factible que tradujese y adaptase a la melodía al mismo tiempo, si bien esto último no sería tampoco absolutamente descartable, teniendo en cuenta que una mujer de su rango y educación podría haber recibido una buena educación musical. De todos modos, esto no aclararía la ausencia de artículos, a no ser que esta peculiaridad se debiese no a Eduvigis sino al autor de los CSG, aunque igualmente cabría pensar en el literalismo para explicarlo. Incluso si llegásemos a pensar que la ausencia de los artículos se hizo por motivos musicales, es decir, que el texto encajase con la melodía como lo haría en latín, el hecho de prescindir de éstos y no de otras palabras seguiría siendo una influencia del latín que podría considerarse como literalismo.

${ }^{18}$ Recordemos que la forma latina de los dos versículos citados, en la Vulgata, es la siguiente:

77) benedicite fontes Domino, laudate et superexaltate eum in saecula

78 ) benedicite maria et flumina Domino, laudate et superexaltate eum in saecula. 